D. Millau in the aspect of the style phenomenon of «provincialisms» in the professional music of the last century. «Provençal provincialism» of the French composer in the «Brazilian dances» and the Suite «Scaramouche» is considered in the series of planetary interest in local dialect phenomena as a source of intensification of the national image of the world. Proposed justification Provençal style D. Millau in the context of the style paradigm of musical art of the twentieth century.

Keywords: provincialism, regionalism in music, dialect style, style, genre.

Стаття надійшла до редакції 11.05.2016

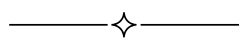

УДК 78.03+78.087.6

Ли Цин

\title{
ВОКАЛЬНЫЕ МИНИАТЮРЫ КЛОДА ДЕБЮССИ 1890-Х ГОДОВ: НОВЫЙ ВЕКТОР ХУДОЖЕСТВЕННЫХ ИСКАНИЙ
}

Камерно-вокальная музыка Дебюсси неизменно привлекает внимание музыковедов. В этом контексте в числе наиболее актуальных оказываются вопросы периодизации вокальных сочинений. Начало 90-х годов ХІХ века открывает новый период творчества Клода Дебюсси. Заканчивается «пора ученичества», изменяется жанровая панорама его музыки (на первый план выходят инструментальные сочинения, устанавливается интерес к оперному жанру), но именно вокальные сочинения этих лет позволяют глубже осознать новые векторы художественных исканий композитора. Этот ракурс рассмотрения вокального наследия К. Дебюсси и определил цель данной статьи: выявить изменения творческих принципов композитора в 90-е годы ХІХ века и уточнить критерии периодизаиии его камерно-вокальных сочинений.

Ключевые слова: Клод Дебюсси, вокальная миниатюра, франиузская музыка 1890-х годов, Стефан Малларме.

Вокальные сочинения Клода Дебюсси давно вошли в репертуар исполнителей и завоевали признание публики. Их неизменное присутствие в современном мире - свидетельство бесспорных художественных открытий одного из главных репрезентантов французской музыкальной культуры конца XIX - начала XX веков. Значимость вокального наследия К. Дебюсси определяется также тем, что в сфере вокальной музыки, как отмечают многие исследователи, осуществлялось формирование индивидуального стиля композитора $[9 ; 12$;

(C) Ли Цин, 2016 
13]. Принципы работы Дебюсси с поэтическим текстом получили продолжение в сочинениях композиторов следующих поколений М. Равеля, Ф. Пуленка, А. Онеггера, О. Мессиана и др. Поэтому камерно-вокальная музыка Дебюсси неизменно привлекает внимание музыковедов $[1 ; 5 ; 6 ; 7 ; 9 ; 12 ; 13$ и др.] и ставит перед ними целый ряд задач в процессе осмысления этой сферы творческой реализации композитора.

В этом контексте в числе наиболее актуальных оказываются вопросы периодизации вокальных сочинений. Несмотря на большой интерес к творчеству Дебюсси зарубежных и украинских исследователей, собственно проблема периодизации его камерно-вокальных произведений специально не ставилась. Начало 90-х годов XIX века открывает новый период творчества Клода Дебюсси. Заканчивается «пора ученичества», изменяется жанровая панорама его музыки (на первый план выходят инструментальные сочинения, устанавливается интерес к оперному жанру), но именно вокальные сочинения этих лет позволяют глубже осознать новые векторы художественных исканий композитора. Этот ракурс рассмотрения вокального наследия 90-х годов и определил цель данной статьи: выявить изменения творческих принципов композитора в 90-е годы XIX века и уточнить критерии периодизации его камерно-вокальных сочинений.

Начало последнего десятилетия XIX века отмечает существенные изменения творческих ориентиров Дебюсси. Симптоматично, что 1890 год начинается с публикации «Пяти поэм Шарля Бодлера». Этот факт обращает на себя особенное внимание, поскольку Дебюсси был чрезвычайно требовательным к себе. В 80-е годы он активно сочинял (на это творческое десятилетие приходится почти половина всех указанных в полном каталоге произведений композитора ${ }^{1}$ ), но его опусы оставались известными только узкому кругу слушателей в парижских салонах. Издание «Пяти поэм Шарля Бодлера» - масштабного вокального цикла, который композитор решил отдать в печать в числе чрезвычайно ограниченного количества ранних сочинений ${ }^{2},-$ сим-

${ }^{1}$ До 1890 года каталог сочинений композитора насчитывает 70 наименований, а общее число всех опусов Дебюсси - 150. Данные приведены по по последнему уточненному каталогу сочинений Дебюсси, составленному Ф. Лезюром [12].

${ }^{2}$ В каталоге произведений К. Дебюсси Ф. Лезюра «Пять поэм Шарля Бодлера» в сквозной нумерации всех ранних сочинений композитора идут под номером 70. Однако до момента их публикации в феврале 1890 года из всего массива первых сочинений были изданы только вокальная миниатюра «Звездная ночь» на стихи Т. де Банвиля 
волически подытожило его первый творческий период, связанный почти исключительно с вокальными жанрами.

Романсы, mŭlodies, вокальные сцены, кантаты, хоры - вот перечень жанров, привлекавших внимание молодого автора. Подчеркнем, что все они связаны со словом. Из 70 произведений Дебюсси, написанных к «Пяти поэмам Шарля Бодлера», только 11 (!) не были предназначены для пения. При этом, за исключением ранних ученических проб, очевидно, что появление невокальных произведений было инспирировано практическими задачами - главным образом, потребностями ансамблевого салонного музицирования ${ }^{1}$.

С начала 90-х годов ситуация меняется. Теперь практически все новые произведения композитор публикует, а его творческие усилия направлены не только на создание вокальной музыки, но захватывают и область инструментальных жсанров. С 1890 года жанровая панорама творчества Дебюсси значительно расширяется. Вокальные сочинения возникают с гораздо большим временным разрывом, а их дальнейшая концертная жизнь представляется не столь успешной, как судьба созданных в начале 90-х годов инструментальных произведений.

Так, в апреле 1890 года Дебюсси заканчивает «Фантазию для фортепиано с оркестром» (Fantaisie pout piano et orchestre) и этом же году создает целую серию фортепианных пьес: «Мечта» (Reverie), «Стирьенская тарантелла» (Tarantelle styrienne), «Славянская баллада» (Ballade (slave)), «Романтический вальс» (Valse romantique), «Марш-экосез на народную тему» (Marche ecossaise sur un thume populaire) в четыре руки. В этом же году композитор начинает работу над «Бергамасской сюитой» (Suite bergamasque), законченной в 1905 году. В 1891 году он пишет «Две арабески» (Deux Arabesques) и «Мазурку» (Mazurka) для фортепиано, начинает работать над симфонической прелюдией «Послеполу-

(1882), клавир для голоса в сопровождении фортепиано лирической сцены «Чудесное дитя» (1884) и «Забытые ариетты» на стихи Поля Верлена» (1888).

${ }^{1}$ В числе 11 ранних невокальных сочинений Дебюсси - «Богемский танец» (Danse bohŭmienne, 1880) для фортепиано; Трио Соль мажор для фортепиано, скрипки и виолончели (Trio en sol majeur, 1880); посвященная Н. Ф. фон Мекк Симфония си минор (Symphonie en si mineur, 1881), сохранившаяся в переложении для фортепиано в 4 руки; Andante cantabile (1881) для фортепиано в 4 руки; увертюра «Диана» (Diane. Ouverture, 1881) для фортепиано в 4 руки; а также оркестровая сюита «Триумф Вакха» (Le Triomphe de Bacchus, 1882), «Ноктюрн и скерцо» для виолончели и фортепиано (Nocturne et scherzo, 1882), «Интермеццо» для фортепиано в 4 руки (Intermezzo, 1882); созданная для экзамена на вилле Медичи «Первая оркестровая сюита» (Premiure Suite d'orchestre, 1883), «Дивертисмент» (Divertissement, 1884) для фортепиано в 4 руки; «Маленькая сюита (Petite suite, 1889-1890) для фортепиано в 4 руки. 
денный отдых фавна» (Prélude a l'Aprus-midi d'un faune, закончена в 1894 году) ${ }^{1}$. В следующем 1892 году появляется «Ноктюрн» для фортепиано (Nocturne en ré bemol), композитор начинает сочинять струнный квартет (Quatuor a cordes, закончен в 1893). В 1894 году Дебюсси создает первый вариант цикла «Образы» для фортепиано (Images) и начинает сюиту «Для фортепиано» (Pour le piano, 1894-1901).

Что же касается вокальных произведений, то в начале 90-х годов появляются лишь одна миниатюра «Красавица в спящем лесу» на стихи Винсена Хиспа (La Belle au bois dormant, 1890), одна миниатюра на стихи Поля Бурже «Прекрасный вечер» (Beau soir, 1890 или 1891), Первая тетрадь «Галантных празднеств» на стихи Поля Верлена (Fêtes galantes, 1891-1892), включающая три миниатюры; mélodie «Ангелы» на стихи Грегуара Ле Роя (Les Angǔlus, 1892); «Лирические прозы» на собственные тексты (Proses lyriques, 1892-1893), состоящие из четырех вокальных номеров.

Сделанный выше обзор ранних произведений Дебюсси красноречиво свидетельствует о том, что с начала 90-х годов жанровые предпочтения композитора сдвигаются с камерно-вокальных на инструментальные. Только за первые годы последнего десятилетия XIX века композитор написал больше инструментальной музыки, чем за одиннадцать предыдущих лет ${ }^{2}$. Кроме того, интересы композитора теперь обращаются к опере. Дебюсси начинает работать над оперой «Родриго и Химена» (1890-1893), однако в письмах постоянно жалуется на трудности в соединении своих музыкальных идей с достаточно громоздким и традиционным либретто Катюля Мендеса. В конце концов, он оставляет оперу незавершенной, открывая весной 1893 года своего «идеального» автора - Мориса Метерлинка ${ }^{3}$ С этого момента почти на десять лет композитор погружается в реализацию

\footnotetext{
${ }^{1}$ В точном переводе название произведения Дебюсси - «Прелюдия к послеполудню фавна». Такой дословный перевод названия использует Л. Кокорева в последней русскоязычной монографии о Дебюсси [6]. Однако сохраним привычное для постсоветского музыкального пространства название «Послеполуденный отдых фавна», которое представляется более благозвучным, а «расшифрованное» в русской версии значение выражения «a l'aprus-midi» как «послеполуденный отдых» представляется вполне возможным в смысловом пространстве стихотворения Малларме.

${ }^{2}$ Первое сочинение, указанное в каталоге произведений Дебюсси, это «Mélodie» на текст Альфреда де Мюссе (конец 1879 года).

${ }^{3} 17$ мая 1893 года Дебюсси присутствовал на единственном спектакле «Пеллеаса и Мелизанды» М. Метерлинка в театре «Les Bouffes parisiens». Годом ранее он уже приобрел напечатанный вариант пьесы и теперь был окончательно очарован произведением бельгийского символиста. Композитор сразу начал работать над созданием музыки.
} 
своего самого масштабного творческого проекта - оперы «Пеллеас и Мелизанда» (закончена в 1902 году).

Дебюсси, вероятно, и сам осознавал новый виток развертывания творческой энергии, на который он вышел в результате тесного общения с наиболее радикально настроенными художественными кругами Парижа. Об этом говорит и постепенный уход Дебюсси от «сотрудничества» с авторитетными поэтами в область безраздельно «индивидуального» разворота творческой фантазии - в сферу «авторской» инструментальной музыки (а в вокальных жанрах - к попытке самому выступить в роли автора литературного текста в «Лирических прозах»); и признание ценности своих музыкальных сочинений (стремление их издавать); и даже «новый взгляд» на себя самого. Красноречивым подтверждением рождения «нового Дебюсси» становится его отказ от повседневного имени Ашиль и использование с декабря 1889 года по июль 1892 года двойного имени Ашиль-Клод или КлодАшиль, а с сентября 1892 года уже привычного для нас имени Клод Дебюсси.

Комментируя этот факт, французский исследователь Ф. Лезюр пишет: «В начале 90-х годов появляется знак, который очевидно отмечает желание перемен у Дебюсси: он отказывается от своего повседневного имени, которое никогда не любил, в пользу имени Клод-Ашиль, которое появляется как новая подпись в разных модификациях и весьма изменчивой графике её начертания» [12, p.109].

Конечно, происходившие изменения отражали не только внешние обстоятельства жизни композитора, но были определены изменениями его художественно-эстетических ориентиров. Благодаря активному обмену идеями с представителями самой раскрепощенной в плане художественных экспериментов части парижского общества, в творчестве молодого и непокорного «Клода Дебюсси - французского музыканта» (как позднее будет гордо именовать себя композитор) закрепляются новые принципы музыкального мышления, обусловившие новаторские художественные решения в сочинениях начала 90-х годов. Творческие эксперименты дерзкого «нарушителя традиций» уже не уйдут из поля внимания французской музыкальной общественности и будут обрастать разного рода скандалами, сопровождавшими Дебюсси до самой смерти.

Как чуткий художник, Дебюсси не мог не откликнуться на новейшие тенденции художественной жизни Парижа конца XIX века. Её особенности получили у французских искусствоведов название 
«конец века» - fin de siucle. Исследуя художественную жизнь Парижа данного периода, С. Яроциньский пишет: «Революция идей 18851895 годов в целом не нашла, однако, надлежащего соответствия в революции форм. Не созрев для охвата всего богатства нового содержания, формы эти под напором иррациональных течений переродились в разного рода маньеризмы, которые вскоре, уже к 1900 году, и расцвели. Художники, вовлеченные в движение, чувствовали себя уверенными до той поры, пока среди них были их духовные вожди (Малларме, Гоген), но когда их не стало, группы, внешне сплоченные, рассеялись, словно стадо заблудших овец» [8, с. 109].

«Витающее в воздухе» эпохи желание осуществить «революцию форм», «освободившись» и от прошлого, и от настоящего, нашло своих адептов и в сфере литературы. Здесь «пророком» и идеологом «нового искусства», решительного обновляющего традиционные подходы к пониманию целей и задач поэзии, стал Стефан Малларме.

Симптоматично, что все зарубежные исследователи акцентируют огромное значение общения Дебюсси с Малларме для формирования творческой индивидуальности композитора. Знакомство Дебюсси с Малларме состоялось осенью 1890 года. Один из знакомых К. Дебюсси - поэт-символист А. Фердинанд Герольд - познакомил Малларме с только что напечатанными «Пятью поэмами Шарля Бодлера». Знаменательно, что вызывавшие недоумение и не пользовавшиеся успехом вокальные миниатюры этого цикла «чрезвычайно поразили Малларме новой красотой» [12, p.115]. Поэт был настолько очарован небывалой выразительностью музыки молодого и практически неизвестного композитора, что решил предложить ему участие в подготовке постановки своего «Последполуденного отдыха фавна» в «Театре искусства» (Théâtre d'art) авангардного режиссера Поля Фора.

Предложение Малларме обнажает существование мгновенно возникшего глубокого творческого резонанса между поэтом и композитором, поскольку музыкальные вкусы Малларме были достаточно необычными. По свидетельству близких друзей, когда он посещал воскресные концерты Ламурё, то не ждал никаких «музыкальных открытий». Пьер Луис говорил о том, что Малларме «приходил туда не для того, чтобы слушать, а чтобы писать. Шум оркестра возбуждал его воображение, совершенно не зависимо от того, чтобы знать, что играют - «Тамбурин» Рамо или «Зигфрид-идиллию» [12, р.115]. Отсюда - неординарные задачи, которые Малларме готов был поставить перед композитором. 
Однако задуманный Малларме спектакль так и не был поставлен на сцене, а запланированная работа композитора по сочинению «Прелюдии, Интерлюдии и Финального Парафраза для «Послеполуденного отдыха фавна» (Prŭlude, Interlude et Paraphrase finale pour l'Aprus-midi d'un faune) ограничилась созданием «Прелюдии», предназначенной для исполнения в Брюсселе в рамках концертов «Свободной эстетики» 1 марта 1894 года. В Брюсселе «Фавн», однако, также не прозвучал и был представлен парижской публике 22 декабря того же года в концерте, организованном Независимым музыкальным обществом (дирижер Г. Доре).

Относительно художественного замысла этого «резонансного» произведения Дебюсси писал: «Музыка Прелюдии является очень свободной иллюстрацией прекрасной поэмы Стефана Малларме. Она не претендует ни на какой синтез с ней. Это скорее последовательные картины, через которые проступают желания и мечты фавна в полуденный зной, который, оставив преследование пугливых нимф и наяд, позволил себе погрузиться в упоительный сон, наполненный сновидениями, в конце концов, реализованными полным обладанием всеобщей природой» [12, р. 515]. Думается, что именно «мечты» и «желания», как зыбкие каналы соединения души с окружающим миром, проявляющие те неуловимые субъектно-объектные связи, о которых столько размышлял Малларме, впервые становятся объектом творческого внимания композитора. Благодаря сотрудничеству с самым таинственным и герметичным французским поэтом эпохи fin de siucle в творчестве Дебюсси закрепляются новые художественные ориентиры, открывавшие новую эру в музыкальном искусстве.

Значение общения с Малларме для творческого пути композитора трудно переоценить. «Открытие контакта Малларме - Дебюсси в конце 1890 года представляет в новом свете не только генезис «Прелюда», но генезис эстетики музыканта», - утверждает Ф. Лезюр [12, p. 116]. Именно влиянию Малларме Дебюсси обязан в наибольшей степени смелостью музыкальных решений в сочинениях начала 90-х годов. Общение с одним из наиболее влиятельных авангардных деятелей французской культуры конца века, знакомство в его доме с талантливыми поэтами-символистами и литераторами Шарлем Морисом, Анри де Ренье, Виеле-Греффеном Пьером Луисом, вероятно, Полем Гогеном окончательно утвердили Дебюсси в намерении говорить новым музыкальным языком, свободным от всяческих ограничений и способным внушить слушателю небывалые впечатления и ощущения. 
Главное влияние Малларме на композитора Яроциньский определяет следующим образом: «Между тем ясно, что, так же как романтики и Бодлер, он стремился ликвидировать границу, отделяющую «я» от «нея». Правда, если те растворялись в панпсихизме или же в пантеизме, Малларме пытался остаться на нейтральной почве познания и в поисках через свою поэзию интенциональных структур в актах сознания надеялся открыть смысл мира в произведении-символе, так как в сущности предполагал всеобщую интенциональность. Он стремился, следовательно, как кто-то остроумно сказал о феноменологии, к абсурдному пределу «глаза, который смотрит сам на себя» [9, с. 66].

Теперь Дебюсси решительно отказывается от академических правил гармонии, которым его учили в консерватории, от сложившихся жанровых стереотипов и, «наблюдая самого себя», фиксирует рождение «нового Дебюсси», не Ашиля, и даже не Клода-Ашиля, но Клода Дебюсси, готового служить самому сокровенному и чистому искусству Музыки. В письме Э. Шоссону 6 сентября 1893 года композитор пишет: «Поистине, музыка должна была бы быть наукой Высшей, охраняемой толкованиями столь длинными и столь трудно понимаемыми, что они обескуражили бы людское стадо, пользующееся ею так же непринужденно, как носовым платком! Итак, и прежде всего, я предлагаю создать Общество музыкального эзотеризма...» [2, с. 44].

Анализ произведений начала 90-х годов, в первую очередь, вокальных жанров, отчетливо проявляет «нового Дебюсси». Это позволяет несколько уточнить традиционную периодизацию творчества Дебюсси, сложившуюся в музыковедческих исследованиях. Как правило, исполнение «Послеполуденного отдыха фавна» в конце 1894 года, сделавшее Дебюсси известным, указывается как начало зрелого периода творчества. Представляется целесообразным обозначить началом нового периода творчества композитора 1890 год (год издания «Пяти поэм Шарля Бодлера», изменения имени и жанровых ориентиров, начала активного общения с Малларме).

В существующей музыковедческой литературе, посвященной Дебюсси, главное внимание в процессе становления индивидуального композиторского стиля исследователи уделяют «Послеполуденному отдыху фавна». Например, авторы фундаментальной «Истории западной музыки» раздел, посвященный Дебюсси, разделяют на параграфы: «Дебюсси до «Прелюдии» (1862-1893) и «Время Пеллеаса» (1894-1902) [10, p. 949-951]. Авторитетный Жан Бараке в монографии «Дебюсси» период между возвращением Дебюсси в Париж из 
Рима и исполнением «Фавна» определяет как «богемный период» и считает, что наши представления о Дебюсси в это время остаются «весьма туманными» [9, p. 85]. Бараке пишет: «В этот период Дебюсси разрывает все связи с консерваторией, институтом и официальной музыкой. С этого момента он испытывает усиливающееся отвращение к официальной музыкальной среде, к которой отказывается принадлежать» [9, p. 90].

Определенный рубеж между ранним «богемным» и «зрелым» Дебюсси проводят через 1894 год и авторы наиболее фундаментального исследования о композиторе Э. Локспайзер и Г. Хальбрейк [12]. Более осторожно периодизацию творчества выстраивает Ф. Лезюр, отмечая-таки значимость 1890 года как по-своему рубежного в творчестве Дебюсси [11].

В свою очередь подчеркнем, что исполнение «Послеполуденного отдыха фавна», конечно, изменило обстоятельства жизни Дебюсси, принесло ему известность и укрепило в осознании своих творческих возможностей и правильности художественных ориентиров. Однако замысел «Фавна» возник намного раньше 1894 года, как и замысел «Пеллеаса», поэтому «привязывать» новый период к опере также представляется не до конца логичным. На наш взгляд, датой, начинающей «зрелый» период творчества композитора, следует считать 1890 год.

Новые художественные ориентиры отчетливо проступают в самом апробированном к этому времени жанре - жанре mŭlodie. Изменения творческих установок особенно ясно видны в процессе сравнения с методом работы композитора над поэтическим текстом в предыдущее десятилетие.

Так, украинская исследовательница С. Луковская, осуществившая детальный анализ вокальных миниатюр Дебюсси на стихи Поля Верлена, указывает на изменения в принципах подхода композитора к поэтическому слову в сочинениях 90-х годов. Сравнивая музыкальные прочтения стихотворений Верлена в 80-е и 90-е годы, исследовательница акцентирует существенное изменение собственно художественной позиции композитора в отношении поэтического текста в процессе создания вокальной миниатюры. «Созданные музыкальные версии трех стихотворений из «Мудрости», - пишет С. Луковская, характеризуют новые творческие устремления композитора. Особенно ярко новые тенденции проявляются в музыкальном прочтении последнего стихотворения, которое свидетельствует о самостоятельности музыкального мышления Дебюсси, который не боится нарушить 
равновесие между функциональной значимостью вокальной и фортепианной партий, закрепившееся в его творчестве в конце 80-х годов. Этот отход композитора от точного следования за поэтическим текстом весьма показателен, поскольку не представляет собой простое возвращение к собственным ранним принципам. Если в первых вокальных миниатюрах свобода обращения с поэтическим текстом была связана с желанием создать выразительную вокальную партию (что допускало распевы слов, повторы поэтических строк, введение вокализов и др.), то теперь над всем доминирует фортепианная партия, которая создает самостоятельный план раскрытия художественного образа. Закономерно, что именно в 90 -е годы усиливается интерес Дебюсси к инструментальным жанрам, уже не связанным со словом, способным самостоятельно решать поставленные художественные задачи» [6, с. 133-134].

Обозначенные выше новые принципы соотношения вокальной и фортепианной партий в вокальном жанре закрепляются в сочинениях 90-х годов. Изменяется и сущность самой вокальной партии. Характеризуя новации Дебюсси, Яроциньский пишет: «Несмотря на то, что чаще всего он использует известный нам по его песням мелодический речитатив, соблюдающий интонационные свойства французской речи и ее акцентуацию, композитор не выступает, однако, невольником этой формулы хотя бы потому, что настроен скорее на улавливание и передачу нам того, что таится под и между словами, чем того, что они значат объективно» [8, с. 184].

Следует подчеркнуть, что главной целью Дебюсси становится реализация его понимания произведения как синтеза всех языков, а также процесса слияния «я» $и$ «не-я», воспринятых композитором в процессе общения с поэтами-символистами. Показательно, что он пишет в письме Раймону Бонеру, 5 октября 1890: «Зачем искать везде прежде всего этикетку и тем низводить себя до уровня вещей, продающихся на базарах? Будем же писать музыку, наполненную всей нашей жизнью, а не маленьким ее уголком, кажущимся нам редкостным только благодаря нашему задранному носу и праздной болтовне тех, кто ею (музыкой) не занимается» [2, с. 36]. Эти новые задачи создания «музыки всей жизни» без границ и преград в полной мере реализуются в самом неординарном и масштабном вокальном опусе начала 90-х годов - «Лирических прозах».

Итак, осознание новой функции слова в вокальном сочинении, обусловливающей смелый поиск новых приемов и принципов прояв- 
ления скрытых уровней развертывания смысла, диктует и новое понимание соотношения вокального (связанного с звучащим словом) и фортепианного (чисто звукового) рядов, а также трактовку гармонической логики как «акустической» системы, свободной от функциональных тональных связей. Новаторские принципы проявляются уже в «Трех стихотворениях» Поля Верлена, но еще более определенно новизна художественной позиции Дебюсси проступает в вокальном цикле «Лирические прозы» (1892-1893), создание которого становится этапом для написания самого масштабного сочинения композитора на прозаический текст - оперы «Пеллеас и Мелизанда».

\section{СПИСОК ЛИТЕРАТУРЫ}

1. Владимирова А. Французская поэзия в вокальном творчестве Дебюсси / А. Владимирова // Дебюсси и музыка XX века: сб. статей. - Л. : Музыка, 1983. - С. 173-192.

2. Дебюсси К. Избранные письма / К. Дебюсси. - Л. : Музыка, 1986. $285 \mathrm{c}$.

3. Дебюсси К. Статьи, рецензии, беседы / К. Дебюсси. - М. ; Л. : Музыка, 1964. $-278 \mathrm{c}$.

4. Егорова Б. Дебюсси и его окружение / Б. Егорова // Музыкальная академия. -2002 . - № 4. - С. 152-157.

5. Кокорева Л. Клод Дебюсси: Исследование / Л. Кокорева. - М. : Музыка, 2010. - $496 \mathrm{c}$.

6. Луковская С. В. Вокальные миниатюры К. Дебюсси на слова П. Верлена в контексте камерно-вокального творчества композитора : дис. ... кандидата искусствоведения : спец. 17. 00. 03. - Музыкальное искусство / Национальная музыкальная академия Украины им. П. И. Чайковского. - Киев, 2005. $-188 \mathrm{c}$.

7. Филенко Г. Вокальная лирика Клода Дебюсси в свете развития жанра / Г. Филенко // Дебюсси и музыка XX века : сб. статей. - Л. : Музыка, 1983. C. $193-247$.

8. Яроциньский С. Дебюсси, импрессионизм и символизм / С. Яроциньский. - М. : Прогресс, 1978. - 224 с.

9. Barraqué J. Debussy / Barraqué Jean. — Paris : Seuil, 1994. - 250 p.

10. Histoire de la Musique Occidentale. Brigitte et Jean Massin. - Paris : Fayard, 1995. - $1312 \mathrm{p}$.

11. Lesure F. Claude Debussy / Lesure François. - Paris : Fayard, 2003. $610 \mathrm{p}$.

12. Lockspeiser E. Debussy. Sa vie et sa pensée. Halbreich Harry. L'ahalyse de l'oeuvre / Lockspeiser Edvard. - Paris ; Fayard, 1989. - 823 p. 
Ли Цін. Вокальні мініатюри Клода Дебюссі 1890-х років: новий вектор художніх пошуків. Камерно-вокальна музика Дебюссі незмінно привертає увагу музикознавців. У цьому контексті в числі найбільш актуальних постають питання періодизації вокальних творів. Початок $90-\mathrm{x}$ років XIX століття відкриває новий період творчості Клода Дебюссі. Закінчується «пора учнівства», змінюється жанрова панорама його музики (на перший план виходять інструментальні твори, з'являється інтерес до оперного жанру), але саме вокальні твори цих років дозволяють глибше усвідомити нові вектори художніх шукань композитора. Цей ракурс вивчення вокальної спадщини Дебюссі і визначив мету статті: виявити зміни творчих принципів композитора в 90-ті роки XIX століття та уточнити критерії періодизації його камерно-вокальних творів.

Ключові слова: Клод Дебюссі, вокальна мініатюра, французька музика 1890-х років, Стефан Малларме.

Li Qing. Vocal miniatures of Claude Debussy of the 1890th years: new vector of art searches. Chamber and vocal music of Debussy steadily draws attention of musicologists. In this context among the most relevant there are questions of a periodization of vocal compositions. The beginning of the 90th years of the 19th century opens the new period of creativity of Claude Debussy. Comes to an end «it is time apprenticeship», the genre panorama of his music (to the forefront there are tool compositions, interest in an opera genre is established) changes, but vocal compositions of these years allow to realize more deeply new vectors of art searches of the composer. This perspective of consideration of vocal heritage of C. Debussy has also defined the purpose of this article: to reveal changes of the creative principles of the composer in the 90th years of the 19th century and to specify criteria of a periodization of his chamber and vocal compositions.

Keywords: Claude Debussy, vocal miniature, French music of the 1890th years, Stephane Mallarmé.

Стаття надійщла до редакції 18.05.2016

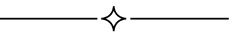

